\title{
Comparative validation of HPLC, densitometric and videodensitometric determination of lamotrigine in pharmaceutical
}

\author{
Beata Paw \\ Chair and Department of Medicinal Chemistry, Medical University of Lublin, Jaczewskiego 4, 20-090 Lublin, Poland
}

\begin{tabular}{|c|c|}
\hline ARTICLE INFO & ABSTRACT \\
\hline $\begin{array}{l}\text { Received } 11 \text { December } 2014 \\
\text { Accepted } 15 \text { December } 2014\end{array}$ & $\begin{array}{l}\text { Simple, sensitive, precise and accurate HPLC, densitometric and videodensitometric } \\
\text { methods for determination of lamotrigine in tablet forms were developed and validated. }\end{array}$ \\
\hline $\begin{array}{l}\text { Keywords: } \\
\text { densitometry, } \\
\text { videodensitometry, } \\
\text { lamotrigine, } \\
\text { tablets. }\end{array}$ & $\begin{array}{l}\text { The HPLC method was carried out using a Symmetry C8 column and a mobile phase } \\
\text { acetonitrile-phosphate buffer } \mathrm{pH} 2.80(25: 75, \mathrm{v} / \mathrm{v}) \text {, with a flow rate of } 1 \mathrm{~mL} / \mathrm{min} \text {, and UV } \\
\text { detection at } 210 \mathrm{~nm} \text {. Ethosuximide was used as the internal standard. Densitometric and } \\
\text { videodensitometric analysis was performed on silica gel } 60 \mathrm{~F} 254 \text { plates, in horizontal } \\
\text { chambers, with methanol-chloroform-ammonia }(25 \%) 1.5: 7.5: 1,(\mathrm{v} / \mathrm{v}) \text { as mobile phase. } \\
\text { Densitometric detection was performed at } 225 \mathrm{~nm} \text { and at } 315 \mathrm{~nm} \text {, and videodeoscanning } \\
\text { at } 254 \mathrm{~nm} \text {. Calibration plots were constructed in the range } 0.5-10 \mu \mathrm{g} / \mathrm{spot} \text {, with good } \\
\text { correlation coefficients } \mathrm{r}>0.99 \text { for both methods. The precision and accuracy of all } \\
\text { elaborated methods were compared. Finally, the developed methods were applied for the } \\
\text { quality control of lamotrigine tablets. }\end{array}$ \\
\hline
\end{tabular}

\section{INTRODUCTION}

Lamotrigine, 6-(2,3-dichlorophenyl)-1,2,4-triazine3,5-diamine (Fig.1) is an anticonvulsant drug used in the treatment of partial and generalized epileptic seizures. It is also used as a mood stabilizer and for the treatment of bipolar depression. Lamotrigine inhibits the voltage-dependent sodium channels, and, thus, prevents the release of excitatory neurotransmitters. In addition, lamotrigine blocks the high voltage-activated calcium channels [2]. Moreover, it is a lipophilic weak base, and it is well absorbed after oral administration.

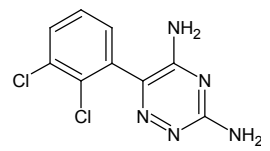

Figure 1. Structure of lamotrigine

In the literature, some concerns are expressed regarding the quantitative analysis of lamotrigine when in pharmaceutical dosage forms. The content of the drug in tablets is normally determined by spectrophotometric $[1,7,10,12]$, spectrofluorimetric [4], HPLC [5,7], HPTLC [7] and capillary electrophoresis [9] methods. The ion-selective electrode method [6] and two different voltammetric techniques: differential pulse adsorptive stripping voltammetry $[3,11]$ and square wave adsorptive stripping voltammetry [3] have also been proposed. In addition, HPLC and TLC methods [13] were normally employed to quantify lamotrigine in the presence of its related impurities, while HPLC [8] alone was used for the evaluation of drug stability under stress conditions.

Lamotrigine is frequently used in the therapy of epilepsy and of bipolar disorder. It is necessary to control the content of lamotrigine in pharmaceuticals, and, therefore, more perfect methods for its determination are still being developed.

The aim of this work was to develop a new, sensitive and precise methods for the routine quantity control of lamotrigine in pharmaceutical products, by way of using HPLC, densitometry and videodensitometry. TLC methods reduce the consumption of reagents and their harmful effects on human health and the environment.

\section{MATERIALS AND METHODS}

Chemicals. Lamotrigine and ethosuximide were purchased from Sigma (St. Louis, MO, USA). Lamotrix tablets 
containing $25 \mathrm{mg}$ lamotrigine per tablet were obtained commercially. Methanol, acetonitrile (Merck, Darmstadt, Germany) and chloroform, 25\% ammonia solution (POCH, Gliwice, Poland) were of analytical reagent grade. The salts used to prepare the phosphate buffer $\left(\mathrm{KH}_{2} \mathrm{PO}_{4}\right.$ and $\left.\mathrm{Na}_{2} \mathrm{HPO}_{4}\right)$ were of "Ultrapure Bioreagent" (JT Baker, UK) grade. The water used in all experiments was fresh double distilled.

HPLC conditions. The Waters HPLC system (Milford, USA) was employed. This consisted of a Waters 515 isocratic pump, the variable wavelength detector Waters 2487 at 210 $\mathrm{nm}$ and a Rheodyne injection valve ( $20 \mu \mathrm{L}$ loop). In addition, the column Symmetry C8 $(5 \mu \mathrm{m}, 4.6 \mathrm{~mm} \times 250 \mathrm{~mm})$ and a mixture of acetonitrile-phosphate buffer $\mathrm{pH} 2.80$ (25:75, $\mathrm{v} / \mathrm{v}$ ) as a mobile phase (with a flow rate $1 \mathrm{~mL} / \mathrm{min}$ ), were used. Ethosuximide was applied as an internal standard.

TLC conditions. All analyses were performed on $20 \mathrm{~cm} \times 10 \mathrm{~cm}$ silica gel $60 \mathrm{~F}_{254}$ TLC plates (Merck, Darmstadt, Germany), using methanol-chloroform-ammonia $(25 \%)$ 1.5:7.5:1 (v/v) as the mobile phase. These plates were then developed at room temperature $\left(20^{\circ} \mathrm{C}\right)$ to a distance of $9 \mathrm{~cm}$, in horizontal Teflon DS chambers (Chromdes, Lublin, Poland). Spots were applied $15 \mathrm{~mm}$ apart and $10 \mathrm{~mm}$ from the lower edge of the plate, by means of a Desaga AS-30 applicator equipped with a Hamilton (USA) syringe.

Densitometry was carried out by means of a Desaga (Heidelberg, Germany) CD 60 densitometer, controlled by Desaga ProQuant software. Spots were scanned at $\lambda=225$ $\mathrm{nm}$ and at $\lambda=315 \mathrm{~nm}$, with slit dimensions of $0.04 \mathrm{~mm} \times$ $6.0 \mathrm{~mm}$.

Videodensitometry was performed at $254 \mathrm{~nm}$, using the Desaga VD40 system comprising of Cab UV-Vis, in conjunction with a high-resolution Mitsubishi color-video CCD camera. The Desaga video-documentation system (Pro-ViDoc, version 3.02), and Desaga software for quantitative analysis (ProResult, version 3.00), were subsequently employed.

Calibration for the HPLC method. The stock solutions of lamotrigine and internal standard (ethosuximide) $(1 \mathrm{mg} /$ $\mathrm{mL}$ ) were prepared in methanol. The working standard solutions of lamotrigine at a concentration of $0.1 \mathrm{mg} / \mathrm{mL}$ were obtained by dilution of stock solutions, using methanol. A series of calibration solutions of lamotrigine were prepared in $10 \mathrm{~mL}$ volumetric flasks, by the appropriate dilution of the working solutions with methanol to reach the concentration range of $0.5-8.0 \mu \mathrm{g} / \mathrm{mL}$. For each sample, $0.2 \mathrm{~mL}$ of the stock solution of ethosuximide was added as an internal standard $(20 \mu \mathrm{g} / \mathrm{mL})$. Each solution was then injected and a chromatogram was recorded. Calibration was performed 5-fold, each time with independent weighing and solvent dilution. The chromatogram obtained from the analysis of lamotrigine calibration solutions is presented in Figure 2.

Calibration for densitometric and videodensitometric methods. Stock solutions $(1 \mathrm{mg} / \mathrm{mL})$ of lamotrigine were prepared in methanol. The working standard solutions $(0.5$ $\mathrm{mg} / \mathrm{mL}$ ) of lamotrigine were made up by appropriate dilutions of stock solutions. Methanolic solutions corresponding to $0.5-10 \mu \mathrm{g}$ of lamotrigine (1-20 $\mu \mathrm{L}$ working solutions) per spot were applied on the plate to perform calibration. Calibration was performed 5-fold, each time with independent weighing and solvent dilution.
Assay in tablets. The average mass of 20 Lamotrix tablets was first determined. The tablets were then ground in a mortar to a fine powder, and the accurately weighted amounts of about $0.1 \mathrm{~g}$ were transferred to $25-\mathrm{mL}$ volumetric flasks containing approximately $15 \mathrm{~mL}$ methanol. After adding the appropriate volume of internal standard (if needed), the mixtures were shaken mechanically for 15 min, diluted to volume with methanol, and subsequently filtered. The resulting solutions were used for densitometric and videodensitometric analysis. Five micro-liters of each solution was applied to TLC plates. The peak areas were then recorded. For HPLC analysis, the filtrate was appropriately diluted before application to the chromatography column. For each elaborated method, the procedure was repeated five times, individually weighing the tablet powder each time.

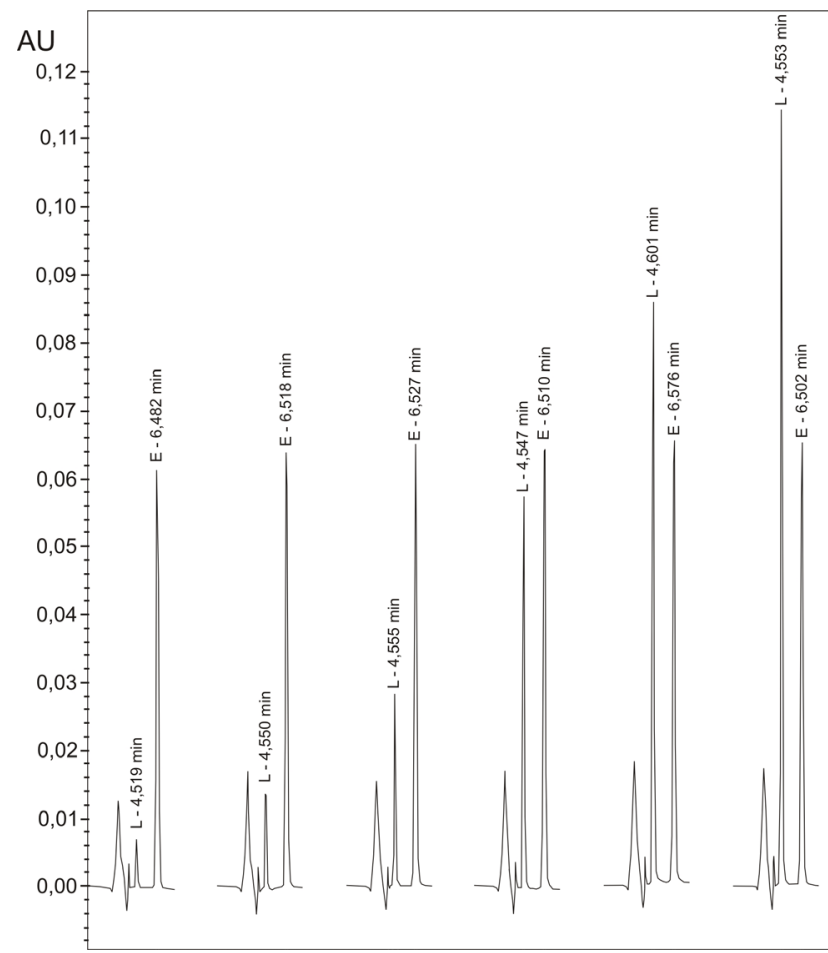

Figure 2. The HPLC chromatogram obtained from analysis of lamotrigine calibration solutions in the range of $0.5-8.0 \mu \mathrm{g} / \mathrm{mL}$; $\mathrm{L}$ - lamotrigine, $\mathrm{E}$ - ethosuximide (internal standard)

\section{RESULTS AND DISCUSSION}

The development of the methods described in this paper required pre-optimization analysis conditions, and different chromatographic conditions were examined (data not shown). The study took into account the best separation of the analytes, the shape of the peaks / spots, selectivity, execution time analysis, linearity, ease of sample preparation, as well as reagents consumption.

A reversed-phase isocratic procedure was proposed as a suitable method for the analysis of lamotrigine in tablet form. Through our research, a mixture of acetonitrile-phosphate buffer $\mathrm{pH} 2.80(25: 75, \mathrm{v} / \mathrm{v})$ at a flow rate $1 \mathrm{~mL} / \mathrm{min}$ was found to be an appropriate mobile phase, as this allowed adequate and rapid separation of the lamotrigine and the internal standard (retention times 4.55 and $6.52 \mathrm{~min}$, respectively). Ethosuximide, chosen as an internal standard, was 
clearly separated from lamotrigine, and the total analysis time was 7.0 min. As shown in Figure 5, the substances, once eluted, formed well-shaped, symmetrical single peaks, well-separated from the solvent front. In the HPLC methods previously presented for the analysis of lamotrigine in tablet forms $[5,7]$ and for the analysis of the presence of impurity [13] and for stability tests under stress conditions [8], an internal standard was not used. This study uses an internal standard - ethosuximide. The addition of the internal standard to the sample before proceeding with the preparation of the samples for chromatographic analysis allows researchers to correct the loss of the analyte. The use of internal standard method also enables independence to be achieved with regard to the results obtained from fluctuations in the amount of injected sample.

Lamotrigine has two maxima of light absorption: a strong one at $210 \mathrm{~nm}$ and a weak one at $308 \mathrm{~nm}$. The wavelength of $210 \mathrm{~nm}$ (at which the best detector response for the analyte was obtained) was selected for the determination of lamotrigine by HPLC.

For the calibration graph, five (5) independent determinations were performed at each of six (6) concentrations. The relationship was subsequently constructed between the peak area ratio of lamotrigine to that of the internal standard and the corresponding concentration, by a linear regression equation:

$$
\begin{gathered}
\mathrm{y}=0.14283( \pm 0.00054) \mathrm{x}-0.00228( \pm 0.00241) \\
\mathrm{r}=0.9999 .
\end{gathered}
$$

The results indicate a good linear proportionality between the detector response and the concentration of lamotrigine.

Our work also developed TLC methods (densitometry at $225 \mathrm{~nm}$ and $315 \mathrm{~nm}$ and videodensitometry at $254 \mathrm{~nm}$ ) for the quantitative determination of lamotrigine in tablet form.

In the densitometric method, the appropriate wavelength for the determination of lamotrigine was determined experimentally using spectrodensitometry. The absorption spectrum of lamotrigine, taken directly from the silica gel plate, showed two absorbance maxima at approximately 225 and $315 \mathrm{~nm}$; these wavelengths were therefore selected for a densitometric evaluation of the drug.

A mobile phase consisting of methanol-chloroformammonia (25\%) (1.5:7.5:1, v/v) was selected as an optimum, and was utilised to obtain sharp and well-defined spots without tailing at $\mathrm{hR}_{\mathrm{F}}=42.82 \pm 0.57$ (mean $\pm \mathrm{SD} ; \mathrm{n}=20$ ).
Calibration was carried out using seven (7) points. For each point, five (5) measurements were made, the data were averaged and calibration curves were calculated. The plot of the peak area versus concentration of lamotrigine was found to be linear in the range of $0.5-10 \mu \mathrm{g}$ per spot. The calibration curves were represented by the following linear regression equations:

$\mathrm{y}_{\text {Dens } 225 \mathrm{~nm}}=320.427( \pm 15.0698) \mathrm{x}+301.401( \pm 84.7229)$
$(\mathrm{r}=0.9945)$

and

$\mathrm{y}_{\text {Dens } 315 \mathrm{~nm}}=410.132( \pm 20.9601) \mathrm{x}+643.001( \pm 117.838)$ $(\mathrm{r}=0.9935)$

and

$\mathrm{y}_{\text {Videodens } 254 \mathrm{~nm}}=1138.64( \pm 63.2532) \mathrm{x}+1087.71( \pm 355.610)$ $(\mathrm{r}=0.9929)$.

The densitogram and video-chromatogram recorded for the calibration solutions are presented in Figures 3A and 4.

An analysis of tablets was performed for five (5) independently weighed samples. Each of these was applied to the plate five (5) times. The results from the analysis of lamotrigine in tablet forms were evaluated statistically; the results are presented in Table 1.

Total recoveries from tablets are $99.78 \pm 0.34 \%$ for HPLC, $100.32 \pm 0.37 \%$ for densitometry $225 \mathrm{~nm}, 99.80$ $\pm 0.56 \%$ for densitometry $315 \mathrm{~nm}$ and $100.63 \pm 0.54 \%$ for videodensitometry $254 \mathrm{~nm}$; the results do not differ from the declared contents (verified by way of the Student's t-test). There was also no interference from the excipients present in the formulation. The HPLC chromatogram of the tablets extract is shown in Figure 5. Densitogram and video-chromatogram obtained during analysis of pharmaceutical formulation are shown in Figures 3B and 4A.Limits to detection (LOD) and quantification (LOQ) of lamotrigine were obtained in both the HPLC and TLC-methods experimentally, taking into account the signal to noise ratio. HPLC shows the best sensitivity; the LOD and LOQ were $0.10 \mu \mathrm{g} /$ $\mathrm{mL}$ and $0.25 \mu \mathrm{g} / \mathrm{mL}$, respectively. The LOD of densitometry, the amount for which the signal-to-noise ratio was $3: 1$, was $0.01 \mu \mathrm{g}$ and $0.005 \mu \mathrm{g}$ per spot for densitometry $225 \mathrm{~nm}$ and densitometry $315 \mathrm{~nm}$, respectively; the LOQ, the amount for which the signal-to-noise ratio was $10: 1$, was $0.02 \mu \mathrm{g}$

\begin{tabular}{|c|c|c|c|c|}
\hline & HPLC & Densitometry $225 \mathrm{~nm}$ & Densitometry $315 \mathrm{~nm}$ & $\begin{array}{c}\text { Videodensitometry } \\
254 \mathrm{~nm} \\
\end{array}$ \\
\hline Amount claimed [mg] & 25 & 25 & 25 & 25 \\
\hline Mean amount found [mg] & 24.9460 & 25.0806 & 24.9495 & 25.1579 \\
\hline Recovery [\%] & 99.78 & 100.32 & 99.80 & 100.63 \\
\hline Variance & 0.00733 & 0.00857 & 0.01921 & 0.01829 \\
\hline Standard deviation [mg/tablet] & 0.0856 & 0.0926 & 0.1386 & 0.1352 \\
\hline Relative standard deviation [\%] & 0.34 & 0.37 & 0.56 & 0.54 \\
\hline 95\% Confidence interval & $24.8397-25.0523$ & $24.9656-25.1956$ & $24.7289-25.1701$ & $24.9899-25.3259$ \\
\hline Difference between the declared and found amounts ( $t$-Student test) & $\begin{array}{c}\text { TV }=-1.411< \\
t_{95 \%, 4}=2.776\end{array}$ & $\begin{array}{l}\text { TV }=1.948< \\
t_{95 \%, 4}=2.776\end{array}$ & $\begin{array}{c}\text { TV }=-0.729< \\
t_{95 \%, 4}=2.776\end{array}$ & $\begin{array}{l}\text { TV }=2.610< \\
t_{95 \%, 4}=2.776\end{array}$ \\
\hline
\end{tabular}

Table 1. Statistical evaluation of results obtained from determination of lamotrigine in pharmaceutical preparations

$\mathrm{TV}=$ the tested value 


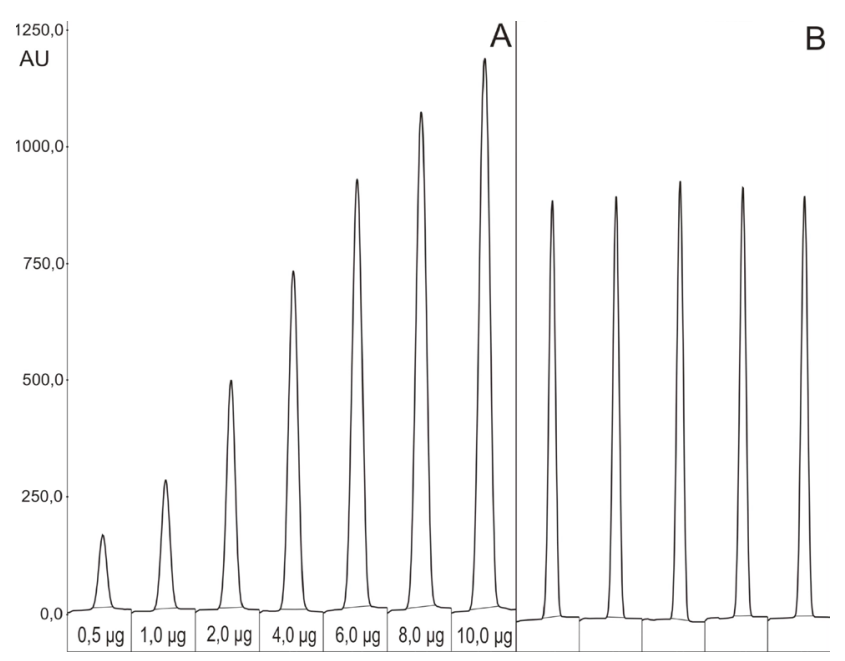

Figure 3. Densitograms obtained from the analysis of lamotrigine standard solutions in the calibration range of $0.5-10.0 \mu \mathrm{g}$ per spot (A), and of tablet samples (B)

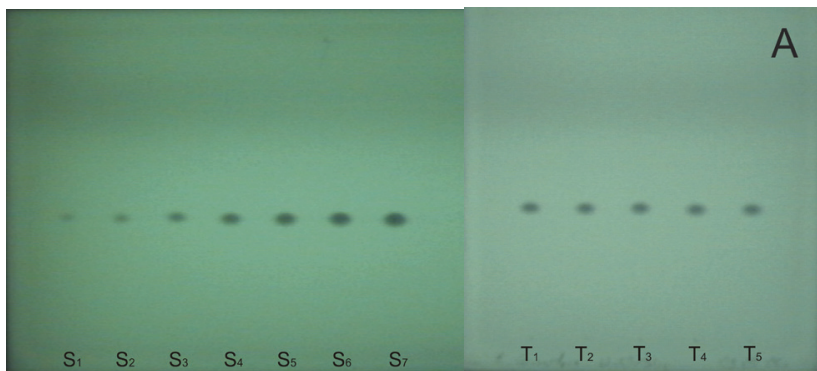

Figure 4. Video-chromatograms obtained from the analysis of lamotrigine calibration solutions (S1 - S7), and of tablet samples $\mathrm{T} 1$ - T5 (A)

per spot for both densitometric methods. In the videodensitometry, the LOD and LOQ were $0.05 \mu \mathrm{g}$ and $0.2 \mu \mathrm{g}$ per spot, respectively.

The precision of the analyzes are expressed using RSD. The best precision was observed in HPLC, and it is higher $(\mathrm{RSD}<0.4 \%)$ than the precision given in current literature regarding the HPLC method when used for determination of lamotrigine in tablets (RSD $<1.8 \%$ [5]; RSD $<1.86 \%$ [7]). The precision of the HPLC method reported by Martins et al. [8] had RSD in the range 0.53 to $1.71 \%$, and by Youssef and Taha [13], RSD $<1.15 \%$. Densitometric and videodensitometric methods also resulted in good precision $(\mathrm{RSD}<1 \%)$, and this result is higher than the precision of employed TLC methods as described previously ( $\mathrm{RSD}=2.19 \%$ [7]; $\mathrm{RSD}=1.30 \%[13])$.

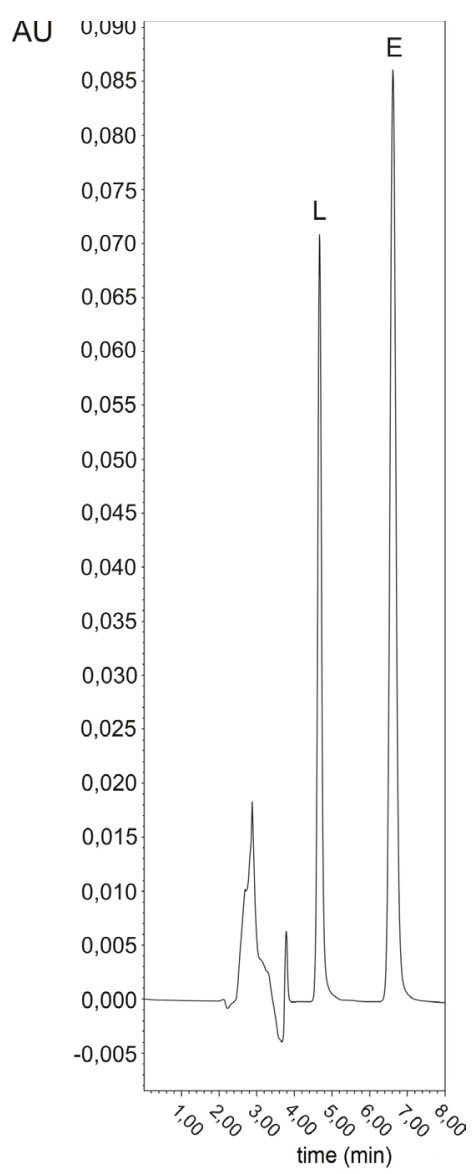

Figure 5. The HPLC chromatogram of lamotrigine (L) and ethosuximide (E) - internal standard, after extraction from Lamotrix tablets

The accuracy of the elaborated methods was assessed on the basis of the determination of lamotrigine in fortified samples at three (3) levels of addition (50, 100, and $150 \%$ of the drug concentration in tablets). For HPLC, the recovery results ranged from 97.69 to $99.77 \%$, with RSD values ranging from 0.97 to $0.51 \%$. For densitometry, the recovery results ranged from $98.24 \%$ (RSD of $2.18 \%$ ) to $101.46 \%$ (RSD of $1.93 \%$ ) at $225 \mathrm{~nm}$, and from $95.12 \%$ (RSD of $2.78 \%$ ) to $101.95 \%$ (RSD of $3.04 \%$ ) at $315 \mathrm{~nm}$. For videodensitometry, the recovery results ranged from 97.27 to $103.54 \%$, with RSD values ranging from 2.05 to $3.17 \%$. Results are the average of five (5) determinations at each level.

The elaborated methods were compared in respect of accuracy and precision, together (Bartlett, ANOVA and

Table 2. Comparison of precision (Bartlett and F-test) and accuracy (ANOVA, Kruskal-Wallis and Wilcoxon tests) of elaborated methods

\begin{tabular}{|c|c|c|c|c|c|c|}
\hline \multirow{2}{*}{ Compared Methods } & \multicolumn{2}{|c|}{ F- Snedecor } & \multicolumn{2}{|c|}{ t-Student } & \multicolumn{2}{|c|}{ Wilcoxon } \\
\hline & $\mathrm{F}$ & $\mathrm{p}$ & $\mathrm{t}$ & $\mathrm{p}$ & w & $\mathrm{p}$ \\
\hline Densitometry $225 \mathrm{~nm}$ - densitometry $315 \mathrm{~nm}$ & 5,3315 & 0,1339 & 0,3281 & 0,75510 & 11 & 0,83403 \\
\hline Densitometry $225 \mathrm{~nm}$ - videoscanning & 1,1000 & 0,9286 & $-1,5559$ & 0,15842 & 5 & 0,15079 \\
\hline Densitometry 315 nm - videoscanning & 4,8468 & 0,1555 & $-2,3943$ & 0,05680 & 2 & 0,03614 \\
\hline Densitometry 225 nm - HPLC & 1,1744 & 0,8799 & 2,3894 & 0,04408 & 22 & 0,05555 \\
\hline Densitometry 315 nm - HPLC & 4,5397 & 0,1720 & 2,8389 & 0,03145 & 23 & 0,03614 \\
\hline Videoscanning - HPLC & 1,0676 & 0,9509 & 4,0706 & 0,00358 & 25 & 0,00793 \\
\hline Bartlett test & \multicolumn{6}{|c|}{$\mathrm{K}^{2}=2,56931, \mathrm{p}=0,46289$} \\
\hline ANOVA test & \multicolumn{6}{|c|}{$F=6,68818, p=0,00389$} \\
\hline Kruskal-Wallis test & \multicolumn{6}{|c|}{$X^{2}=11,37427, p=0,00986$} \\
\hline
\end{tabular}


Kruskal-Wallis tests) and pairwise using the F-Snedecor, $\mathrm{t}$-Student or Wilcoxon test. The results are presented in Table 2.

There are no differences in precision of all compared methods (Bartlett test). Precision of the methods, compared pairwise show no differences (F-Snedecor test) and the accuracy is significantly different only between: densitometry $315 \mathrm{~nm}$ and HPLC, videodensitometry and HPLC.

\section{CONCLUSION}

The proposed HPLC, densitometric and videodensitometric methods are simple, sensitive and precise. They were successfully applied for the determination of lamotrigine in tablet forms. High recoveries of analyte and low coefficients of variation confirm the suitability of the elaborated methods for the routine analysis of lamotrigine in pharmaceutical products.

\section{REFERENCES}

1. Alizadeh N., Khakinahad R., Jabbari A.: Spectrophotometric determination of lamotrigine in pharmaceutical preparations and urine by charge-transfer complexation. Pharmazie, 63, 791, 2008.

2. Bialer M. et al.: Progress report on new anti-epileptic drugs: a summary of the Eighth Eilat Conference (EILAT VIII). Epilepsy Res., 73, 1, 2007.

3. Calvo M.E.B., Renedo O.D., Martinez M.J.A.: Optimization of the experimental parameters in the determination of lamotrigine by adsorptive stripping voltammetry. Analytica Chimica Acta, 549, 74, 2005.
4. El-Enany N.M. et al.: Validated spectrofluorimetric method for the determination of lamotrigine in tablets and human plasma through derivatization with o-phthalaldehyde. J. Fluoresc. 20, 463, 2010.

5. Emami J., Ghassami N., Ahmadi F.: Development and validation of a new HPLC method for determination of lamotrigine and related compounds in tablet formulations. J. Pharm. Biomed. Anal., 40, 999, 2006.

6. Gupta V.K., Singh A.K., Gupta B.: Development of membrane electrodes for selective determination of some anti-epileptic drugs in pharmaceuticals, plasma and urine. Anal. Bioanal. Chem., 389, 2019, 2007.

7. Koba M. et al.: Determination of lamotrigine in tablets using HPTLC, HPLC, and derivative spectrophotometry methods. J. Liq. Chromatogr. \& Rel. Technol., 36, 537, 2013.

8. Martins M.T., Paim C.S., Steppe M.: LC and UV methods for lamotrigine determination in pharmaceutical formulation. Chromatography Research International, Article ID 860168, 2011.

9. Paw B., Matysiak J., Kowalczuk D.: Development and validation of a capillary electrophoresis method for the determination of lamotrigine in pharmaceutical dosage form. Ann. UMCS Sect. DDD, 24, 9, 2011.

10. Rajendraprasad N., Basavaiah K., Vinay K.B.: Micro and nanogram determination of lamotrigine in pharmaceuticals by visible spectrophotometry, using bromophenol blue. Indian Journal of Chemical Technology, 17, 220, 2010.

11. Renedo O.D, Calvo M.E.B., Martinez M.J.A.: Determination of lamotrigine in pharmaceutical preparations by adsorptive stripping volammetry, using screen printed electrodes. Sensors, 8, 4201, 2008.

12. Vinay K.B. et al.: Sensitive, selective and extraction-free spectrophotometric determination of lamotrigine in pharmaceuticals, using two sulphonthalein dyes. Thai J. Pharm. Sci., 35, 65, 2011.

13. Youssef N.F., Taha E.A.: Development and validation of spectrophotometric, TLC and HPLC methods for the determination of lamotrigine in the presence of its impurity. Chem. Pharm. Bull., 55, 541, 2007. 